\title{
Oral Delivery of Nisin in Resistant Starch Based Matrices Alters the Gut Microbiota in Mice
}

\author{
Ronan Gough ${ }^{1,2}$, Raúl Cabrera Rubio ${ }^{1,3}$, Paula M. O'Connor ${ }^{1,3}$, Fiona Crispie ${ }^{1,3}$, \\ André Brodkorb ${ }^{1}$, Song Miao ${ }^{1}$, Colin Hill ${ }^{2,3}$, Reynolds P. Ross ${ }^{3,4}$, Paul D. Cotter ${ }^{1,3}$, \\ Kanishka N. Nilaweera ${ }^{1 *}$ and Mary C. Rea ${ }^{1,3}$ \\ ${ }^{1}$ Teagasc Food Research Centre, Fermoy, Ireland, ${ }^{2}$ School of Microbiology, University College Cork, Cork, Ireland, ${ }^{3}$ APC \\ Microbiome Ireland, University College Cork, Cork, Ireland, ${ }^{4}$ College of Science, Engineering, and Food Science, University \\ College Cork, Cork, Ireland
}

OPEN ACCESS

Edited by:

Rustam Aminov,

University of Aberdeen,

United Kingdom

Reviewed by:

Christophe Lacroix

ETH Zürich, Switzerland

George Grant,

University of Aberdeen,

United Kingdom

${ }^{*}$ Correspondence:

Kanishka N. Nilaweera kanishka.nilaweera@teagasc.ie

Specialty section:

This article was submitted to Antimicrobials, Resistance and Chemotherapy,

a section of the journal

Frontiers in Microbiology

Received: 27 February 2018 Accepted: 16 May 2018

Published: 15 June 2018

Citation:

Gough R, Cabrera Rubio R, O'Connor PM, Crispie F, Brodkorb A, Miao S, Hill C, Ross RP, Cotter PD, Nilaweera KN and Rea MC (2018)

Oral Delivery of Nisin in Resistant Starch Based Matrices Alters the Gut Microbiota in Mice.

Front. Microbiol. 9:1186.

doi: 10.3389/fmicb.2018.01186
There is a growing recognition of the role the gastrointestinal microbiota plays in health and disease. Ingested antimicrobial proteins and peptides have the potential to alter the gastrointestinal microbiota; particularly if protected from digestion. Nisin is an antimicrobial peptide that is used as a food preservative. This study examined the ability of nisin to affect the murine microbiota when fed to mice in two different starch based matrices; a starch dough comprising raw starch granules and a starch gel comprising starch that was gelatinized and retrograded. The effects of the two starch matrices by themselves on the microbiota were also examined. Following 16S rRNA compositional sequencing, beta diversity analysis highlighted a significant difference $(p=0.001, n=10)$ in the murine microbiota between the four diet groups. The differences between the two nisin containing diets were mainly attributable to differences in the nisin release from the starch matrices while the differences between the carriers were mainly attributable to the type of resistant starch they possessed. Indeed, the differences in the relative abundance of several genera in the mice consuming the starch dough and starch gel diets, in particular Akkermansia, the relative abundance of which was 0.5 and $11.9 \%$, respectively ( $p=0.0002, n=10$ ), points to the potential value of resistance starch as a modulator of beneficial gut microbes. Intact nisin and nisin digestion products (in particular nisin fragment 22-31) were detected in the feces and the nisin was biologically active. However, despite a three-fold greater consumption of nisin in the group fed the nisin in starch dough diet, twice as much nisin was detected in the feces of the group which consumed the nisin in starch gel diet. In addition, the relative abundance of three times as many genera from the lower gastrointestinal tract (GIT) were significantly different $(p<0.001, n=10)$ to the control for the group fed the nisin in starch gel diet, implying that the starch gel afforded a degree of protection from digestion to the nisin entrapped within it.

Keywords: mouse, nisin, starch, resistant starch, microbiota, digestion, Akkermansia 


\section{INTRODUCTION}

The gastrointestinal microbiota impacts on the health of the host in variety of ways, including through its potential to protect against infection, provide nutrients, and influence on bodyweight (Clarke et al., 2012; Nicholson et al., 2012; Jandhyala et al., 2015). The composition of the microbiota, and thus its health effects, can be altered by a variety of means, including antimicrobials and diet (Martínez et al., 2010; Cotter et al., 2012; Chung et al., 2016).

Nisin is an antimicrobial peptide with broad activity against Gram positive bacteria produced by strains of Lactococcus lactis subsp. lactis (Abee and Delves-Broughton, 2003). Nisin has been approved for use as a food preservative by both US Food and Drug Administration, (FDA) (US Food and Drug Administration, 1988) and by the European Food Safety Authority (EFSA) with its assigned E number being E 234 (Younes et al., 2017).

Nisin is very stable at low $\mathrm{pH}$ and at $\mathrm{pH} 3$ there is $<5 \%$ loss of activity when heated to $115^{\circ} \mathrm{C}$ for $20 \mathrm{~min}$ (Davies et al., 1998). However, while relatively resistant to passage through the acidic conditions in the stomach, nisin can be digested by pancreatin in the small intestine (Heinemann and Williams, 1966; Gough et al., $2017 b$ ), primarily by its trypsin and chymotrypsin components and therefore may not reach the lower gastrointestinal tract (GIT) in an intact form (Jarvis and Mahoney, 1969; Chan et al., 1996).

Few in vivo studies (Table 1) have investigated how dietary supplementation with nisin affects the microbiota of the lower GIT (Bernbom et al., 2006; Józefiak et al., 2013; Lauková et al., 2014; Kieronczyk et al., 2016) and no previous in vivo study has employed a high throughput sequencing (HTS)based approach to examine the impact of nisin on the entire microbiota. Nisin has been consumed in vivo at up to $239 \mathrm{mg}$ per $\mathrm{kg}$ body weight per day without any adverse effects on food consumption, body weight, hematology, ophthalmology, or gross pathology (Hagiwara et al., 2010). Although nisin doses of up to $173.9 \mathrm{mg}$ per $\mathrm{kg}$ body weigh per day had no impact on the microbiota in a study on rats (Bernbom et al., 2006), nisin has been seen to influence the microbiota in some way in the majority of in vivo studies including those on mice, chickens and rabbits and in in vitro bovine and human microbiota studies (Table 1). However, the variation in methods used, and the previous absence of detailed HTS-based investigations, make direct comparisons difficult (Table 1).

Starch is the primary carbohydrate source in the adult western diet (Sibley, 2004). Starch is comprised of the carbohydrate polymers amylose and amylopectin, and in plants these are arranged into semi-crystalline starch granules, which are of $0.1-$ $200 \mu \mathrm{m}$ in diameter. When "raw" starch granules are suspended in water and heated, the amylose, and amylopectin disassociate, with the granules leaching amylose and absorbing water causing them to swell and ultimately dissipate. When the solution is subsequently cooled, the amylose and amylopectin re-associate, turning the solution into a starch gel, with the gel strength primarily determined by amylose content. These two stages are referred to as gelatinization and retrogradation (AlcázarAlay and Meireles, 2015; Wang et al., 2015). Many types of food processing, including cooking, can cause starch to undergo gelatinization and retrogradation (Delcour et al., 2010) with copresent substances becoming entrapped in the resulting starch gel (Forssell, 2004).

The portion of starch that resists digestion in the small intestine is termed "resistant starch" and varies between starch source and type. In the case of the type of starch used in this study (70\% amylose starch from maize), the resistant starch content has been reported as $46 \%$ on a w/w basis (McCleary et al., 2002). Starch that is resistant due to its granular nature is classified as type 2 resistant starch (RS2), whereas starch that is resistant due to retrogradation is classified as type 3 resistant starch (RS3) (Sajilata et al., 2006). Due to the capacity of the resistant starch portion of a starch to resist digestion in the upper GIT and subsequently be fermented by colonic bacteria, starch based systems have been proposed for the colonic delivery of drugs and bioactive materials; these systems frequently use ethyl cellulose as a binder and are frequently produced through spray coating (Milojevic et al., 1996; Dimantov et al., 2004; Desai, 2005; Wilson and Basit, 2005; Freire et al., 2010; Pu et al., 2011; Situ et al., 2014; Recife et al., 2017).

The aim of this study was to determine the effect, in vivo, of orally consumed nisin on the lower GIT microbiota (as determined by $16 \mathrm{~S}$ rRNA HTS of fecal samples; Suzuki and Nachman, 2016) when nisin was incorporated into two different starch based matrices; a dough based on raw starch (RS2) and a gel based on starch that had undergone gelatinization and retrogradation (RS3). Additionally the potential of the starch matrices themselves to impact on the microbiota was examined.

\section{MATERIALS AND METHODS}

\section{Reagents}

High amylose corn starch (HACS) was obtained from Sigma Aldrich (S4180, Sigma Aldrich, Arklow, Ireland). Dextrose equivalent 12 maltodextrin (DE12 MD) was obtained from Roquette (Glucidex ${ }^{\circledR}$ 12, Roquette, Corby, UK). All other reagents were from Sigma Aldrich (Arklow, Ireland) unless otherwise specified.

\section{Preparation of Nisin}

The nisin A preparation used in this study was Nisaplin ${ }^{\circledR}$ (DuPont, Beaminster, UK). This preparation was concentrated by salting out as previously described (Gough et al., 2017a). This resulted in a $57.7 \%$ nisin preparation which will subsequently be referred to in the text as enriched nisin.

\section{Preparation of Test Diet Pellets}

Starch gels were prepared with and without nisin as follows. Starch gels with nisin were composed of $1 \%(\mathrm{w} / \mathrm{w})$ enriched nisin, $44 \%(\mathrm{w} / \mathrm{w}) \mathrm{HACS}$, and $55 \%(\mathrm{w} / \mathrm{w})$ dilute $\mathrm{HCl}$, with a final $\mathrm{pH}$ of 3. Starch gels without nisin were composed of $45 \%(\mathrm{w} / \mathrm{w})$ HACS and $55 \%(\mathrm{w} / \mathrm{w})$ dilute $\mathrm{HCl}$, with a final $\mathrm{pH}$ of 3 . The suspensions were split into $10 \mathrm{~mL}$ aliquots, heated at $115^{\circ} \mathrm{C}$ for $15 \mathrm{~min}$ and subsequently incubated at $4^{\circ} \mathrm{C}$ for a minimum of $16 \mathrm{~h}$ to ensure thorough retrogradation. Starch dough was prepared with and without nisin as follows. The starch dough balls with nisin comprised 1\% (w/w) enriched nisin, 51.5\% (w/w) HACS, 


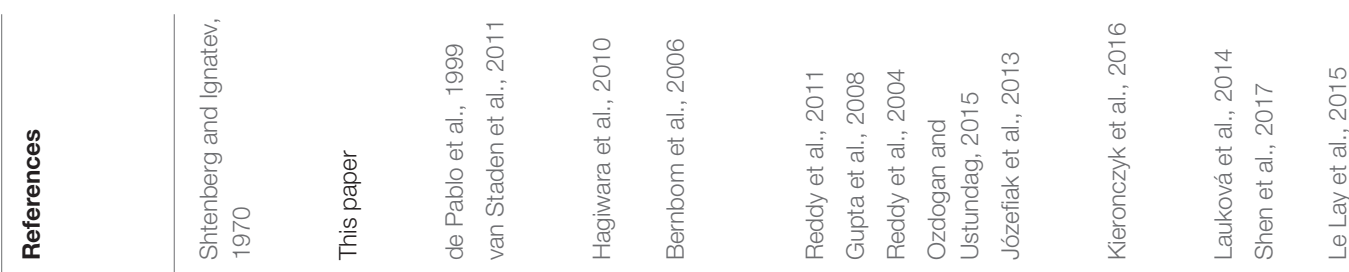

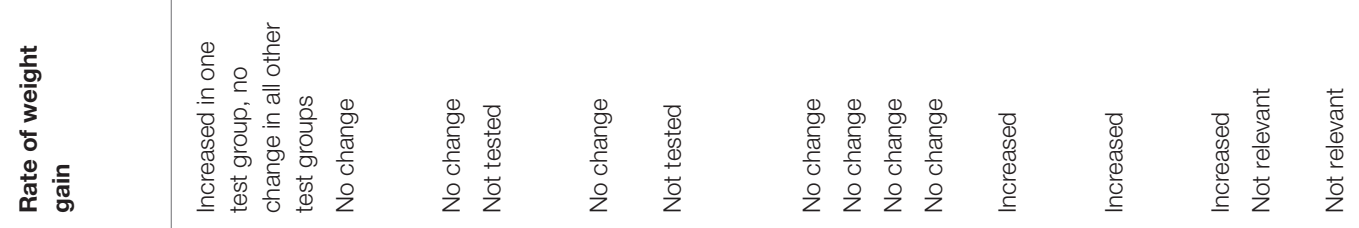

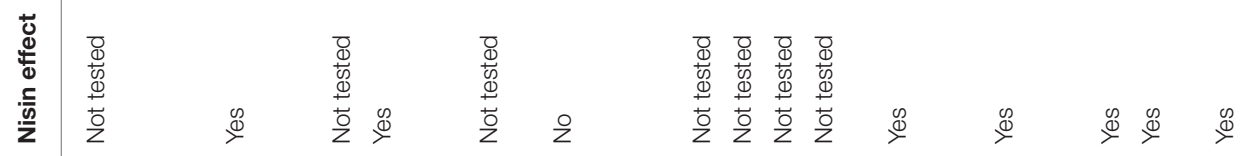

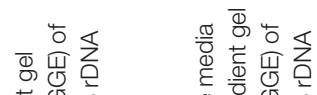

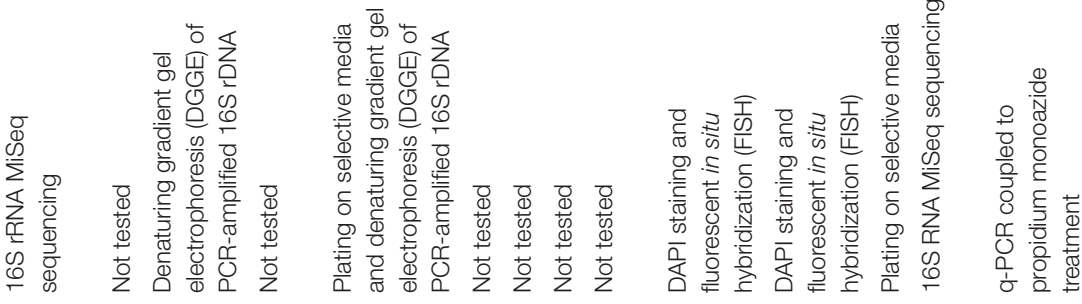

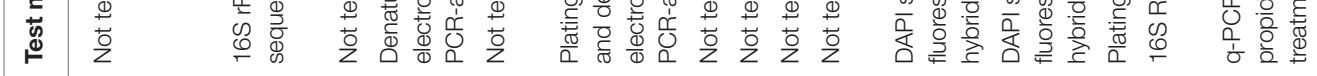

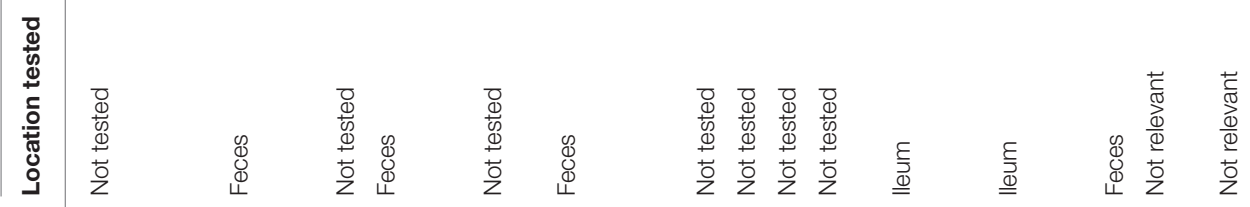

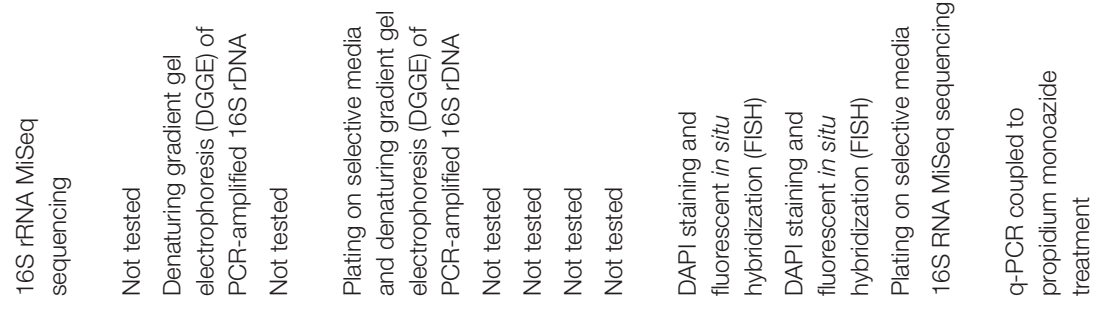

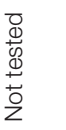

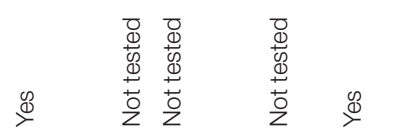

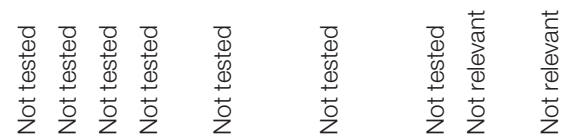

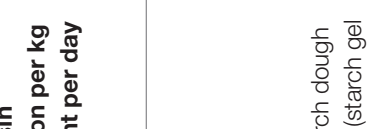

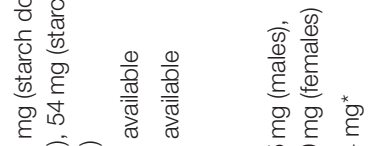

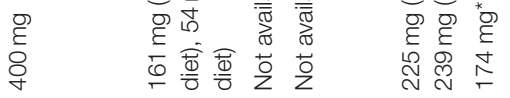

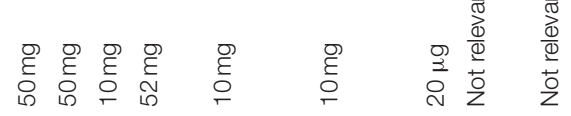

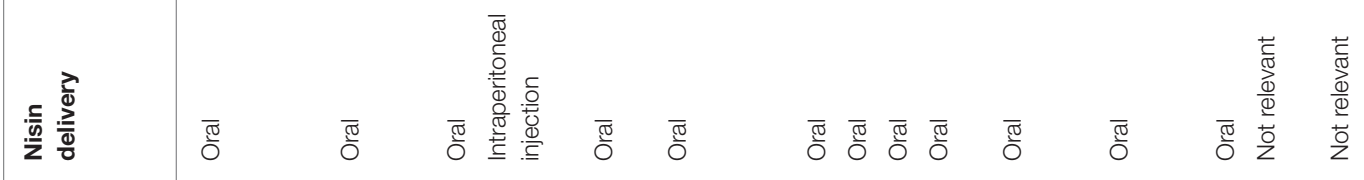

(5) 
22.5\% DE12 MD, and 25\% (w/w) dilute $\mathrm{HCl}$. The starch dough balls without nisin contained 52.5\% (w/w) HACS, $22.5 \%$ DE12 $\mathrm{MD}$, and $25 \%(\mathrm{w} / \mathrm{w})$ dilute $\mathrm{HCl}$. For the preparation of the nisin containing starch dough balls, the dilute HCL and enriched nisin (at $\mathrm{pH} 3$ ) were heated at $115^{\circ} \mathrm{C}$ for $15 \mathrm{~min}$ and allowed cool to room temperature before addition to the rest of the ingredients, to ensure that the treatment of the nisin in the starch dough was comparable with that of the nisin in the starch gel. All the components of the starch dough balls were then mixed in a laminar flow cabinet. Each starch dough ball was thoroughly kneaded to achieve homogeneity and firmness. The starch dough balls were stored at $4^{\circ} \mathrm{C}$ until use.

\section{Feeding Schedule and Sample Collection}

This study was carried out in accordance with European Directive 2010/63/EU. The protocol was approved by the University College Cork Animal Experimentation Ethics Committee (2011/005). Male C57BL/6JOlaHsd mice aged 3-4 weeks (Envigo, Alconbury, UK) were group housed (5 per cage) and were maintained in a 12:12 h light-dark cycle. During the initial 10 day acclimatization period, the mice were fed a standard nutritionally complete low-fat rodent diet (D12450B, Research Diets, New Brunswick, New Jersey, US); this diet is henceforth referred to as the nutritionally complete (NC) diet. Subsequently weight matched mice were assigned to receive the following test diets: starch dough (SD), starch dough containing nisin (SD-N), starch gel (SG), and starch gel containing nisin (SG-N) ( $n=10$ per test diet).

An overview of the feeding schedule is shown in Table 2. The feeding schedule involved initially switching the NC diets with the test diets for $2 \mathrm{~h}$ per day for 3 days and this was gradually increased to $8 \mathrm{~h}$ per day over the period of the trial as described in Table 2. The test diets were introduced gradually to acclimatize the animals to eating the starch based diets. The exposure to the NC diets thus decreased from 22 to $16 \mathrm{~h}$ per day over the period of the trial. The test diets were replaced every 4 days to ensure the freshness of the diet pellets. As mice are nocturnal animals and the cage room was on a 12:12 h light-dark cycle, the food hoppers were switched to test diets at the beginning of the dark cycle (18:00). The food hoppers were weighed throughout the trial as described in Table $\mathbf{2}$ and additional food hoppers in empty cages were used as controls to measure the impact of diet pellet drying on diet pellet weight. The hoppers were loaded with sufficient pellets of the test and NC diets to ensure that a sufficient quantity of test/NC diet was provided to the mice for ad libitum consumption at all times.
The mice were weighed and fecal pellets collected during the course of the experiment as outlined in Table 2. At these time points fecal pellets were obtained from each mouse and stored at $-80^{\circ} \mathrm{C}$ individually for $16 \mathrm{~S}$ RNA sequencing. For MALDI TOF mass spectroscopy, HPLC and activity assays composite fecal samples were obtained by pooling the fecal pellets by cage at each time point. To limit contamination of the samples, the fecal pellets were collected directly from the mice and not from the bedding.

\section{DNA Extraction, Amplification, and Sequencing}

DNA was extracted from fecal pellets using a QIAamp ${ }^{\circledR}$ Fast DNA Stool Kit (Qiagen, Crawley, UK) according to the manufacturer's instructions with some modifications. To increase DNA yield, after the addition of InhibitEX buffer, bead beating $(3 \mathrm{~min} \times 2)$ and an incubation at $95^{\circ} \mathrm{C}$ for $5 \mathrm{~min}$, were performed. The samples were quantified using a Qubit ${ }^{\circledR}$ dsDNA High Sensitivity Assay Kit (Fisher Scientific, Dublin, Ireland) in conjunction with a Qubit ${ }^{\circledR} 2.0$ fluorometer (Invitrogen, Paisley, UK). The initial amplification PCRs were performed as outlined in the Illumina 16S Metagenomic Sequencing Library Preparation Guide (Illumina, Saffron Walden, UK) with the following alterations; 30 amplification cycles were used and the amplification PCRs were each performed in a total volume of $60 \mu \mathrm{L}$ which contained $25 \mathrm{ng}$ DNA and $1 \mu \mathrm{L}$ of each primer at a $10 \mu \mathrm{M}$ concentration. The subsequent clean up using the AMPure ${ }^{\circledR}$ XP purification system (Labplan, Dublin, Ireland) was scaled up appropriately to account for the greater volume. The index PCRs and subsequent AMPure ${ }^{\circledR}$ XP clean up were as outlined in the Illumina protocol. The samples were quantified using the Qubit ${ }^{\circledR}$ procedure and the concentrations normalized to $20 \mathrm{nM}$ and pooled as per the Illumina protocol. The pooled sample $(100 \mu \mathrm{L})$ was purified using AMPure ${ }^{\circledR}$ XP beads and the sample eluted using $50 \mu \mathrm{L}$ of a $10 \mathrm{mM}$ Tris solution. The pooled sample was quantified using the Qubit ${ }^{\circledR}$ procedure and sample quality was determined using an Agilent 2100 Bioanalyzer (Agilent, Cork, Ireland). The pooled sample was denatured and sequenced using a 500 cycle v2 kit on the MiSeq ${ }^{\text {TM }}$ sequencing platform (Illumina, Saffron Walden, UK) following protocols outlined by Illumina at the Teagasc Sequencing Centre, Moorepark.

\section{Bioinformatics Analysis}

Sequences were filtered on the basis of quality (removal of low quality nucleotides at the $3^{\prime}$ end) and length (removal

TABLE 2 | Feeding schedule and days of fecal pellet collection and mouse and food hopper weighing.

\begin{tabular}{|c|c|c|c|c|c|c|c|c|c|c|c|c|c|c|c|c|}
\hline Day & 1 & 2 & 3 & 4 & 5 & 6 & 7 & 8 & 9 & 10 & 11 & 12 & 13 & 14 & 15 & 16 \\
\hline Fecal pellet collection & $\checkmark$ & & & & $\checkmark$ & & & & $\checkmark$ & & & $\checkmark$ & & & $\checkmark$ & \\
\hline Mice weighed & $\checkmark$ & $\checkmark$ & & $\checkmark$ & & & & $\checkmark$ & & & $\checkmark$ & & & & & $\checkmark$ \\
\hline Food hopper weighed & $\checkmark$ & $\checkmark$ & & $\checkmark$ & $\checkmark$ & $\checkmark$ & $\checkmark$ & $\checkmark$ & $\checkmark$ & $\checkmark$ & $\checkmark$ & $\checkmark$ & $\checkmark$ & $\checkmark$ & $\checkmark$ & $\checkmark$ \\
\hline Hours on test diet & 2 & 2 & 2 & 4 & 4 & 4 & 4 & 4 & 6 & 6 & 6 & 8 & 8 & 8 & 8 & $\mathrm{n} / \mathrm{a}$ \\
\hline Hours on nutritionally complete diet & 22 & 22 & 22 & 20 & 20 & 20 & 20 & 20 & 18 & 18 & 18 & 16 & 16 & 16 & 16 & $\mathrm{n} / \mathrm{a}$ \\
\hline
\end{tabular}


of sequences with $<200 \mathrm{nt}$ ) with PRINSEQ (Schmieder and Edwards, 2011) and joined using fastq-join (Aronesty, 2011). The sequences were clustered with $97 \%$ identity level (calculated at the operational taxonomic unit; OTUs) using closed-reference USEARCH v7.0 algorithm (Edgar, 2010) against the Ribosomal Database Project (Wang et al., 2007). Alpha and beta-diversity was determined using QIIME (Caporaso et al., 2010). The results of principal coordinates analysis (PCoA) of the beta-diversity when it was calculated using distance matrices built from unweighted UniFrac distances, were visualized using EMPeror (Vázquez-Baeza et al., 2013).

\section{Preparation of Fecal Pellets for Detection of Nisin}

To detect nisin in the fecal pellets, the nisin was extracted from the pellets as described by Rea et al. (2014) with minor modifications as follows: composite fecal samples were suspended in $1 \mathrm{~mL}$ of $0.1 \%$ TFA and $70 \%$ IPA, vortexed thoroughly and allowed to stand at room temperature for $30 \mathrm{~min}$ and centrifuged for $5 \mathrm{~min}$ at $16,000 \times g$ and the supernatant retained. The centrifugation step was repeated a further three times with the supernatant retained each time. In order to bring the IPA content of the samples to $<7 \%$, IPA was removed using a Centrivap Console (Labconco, Kansas City, US) and the samples were then restored to their original volumes using $0.1 \%$ TFA.

\section{Reversed Phase-High Performance Liquid Chromatography (RP-HPLC)}

RP-HPLC was carried out on a Jupiter, $5 \mu \mathrm{m}, \mathrm{C} 18,300 \AA$, 250 $\times 4.6 \mathrm{~mm}$ column from Phenomenex (Macclesfield, UK) with an acetonitrile (Thermo Fisher Scientific, Dublin, Ireland) gradient as described previously (Gough et al., 2017a).

\section{Matrix-Assisted Laser Desorption/lonization Time of Flight Mass Spectroscopy (MALDI TOF MS)}

The molecular mass of the HPLC fraction corresponding to the nisin peak was determined using MALDI TOF MS using an Axima $\mathrm{TOF}^{2}$ (Shimadzu Biotech, Kyoto, Japan) as previously described (Field et al., 2012).

\section{Activity Assay}

Antibacterial activity was estimated by agar diffusion activity assays (Ryan et al., 1996) in agar plates seeded with L. lactis subsp. cremoris HP as described previously (Gough et al., 2017a). Nisin was extracted from the fecal pellets as described above and Tween ${ }^{\circledR} 80$ was added to a final concentration of $1 \%$ to prevent nonspecific adsorption of the nisin. The samples were dispensed into the wells of the seeded agar in $50 \mu \mathrm{L}$ aliquots and the plates incubated overnight at $30^{\circ} \mathrm{C}$. Antibacterial activity resulted in zones of inhibition surrounding the wells. Nisin was quantified based on a published method (Bernbom et al., 2006) by plotting the area of the zone of inhibition against the log of the nisin concentration of a serial dilution of Nisaplin ${ }^{\circledR}$ that was suspended in an equivalent solution to the samples (6\% IPA, $0.1 \%$ TFA, $1 \%$ Tween ${ }^{\circledR} 80$ ), to generate a linear standard curve.

\section{Statistical Analysis}

Data was tested for normality of distribution using the ShapiroWilk test. For comparing two groups Student's $t$-test or MannWhitney $U$-test were used as appropriate and for comparison of multiple groups one-way ANOVA or Kruskal-Wallis test were used as appropriate, additionally analysis of beta diversity was performed using the Adonis function in the $\mathrm{R}$ package Vegan (Oksanen et al., 2015). Analysis of the bioinformatics data was performed using the R statistical package (R Core Team, 2015) and all other analysis was performed using the SigmaStat software (Systat Software, San Jose, US). Results are expressed as mean \pm standard error.

\section{RESULTS}

\section{Quantity of Diets Consumed and Effect on Weight Gain}

The cumulative consumption of the $\mathrm{NC}$ and test diets and resultant body weight gain are shown in Figure 1. There were no significant differences in body weight gain or in NC diet consumption between diet groups over the trial period with three exceptions, each of which occurred only at a single measurement time point; the consumption of the NC partner diet for SD and SG-N in the $6 \mathrm{~h}$ consumption period was significantly different ( $p=0.02, n=6$ ), the weight gain for the mice on the SG and SG-N diets from days 4 to 7 of the trial was significantly different ( $p=0.02, n=10)$ and the weight gain for the mice on the SD and SG diets from days 11 to 15 of the trial was significantly different $(p=0.0004, n=10)$. The total consumption per cage of the SD-N and SG-N test diets was $20.8 \pm 2.5$ and 6.5 $\pm 2.0 \mathrm{~g}$, respectively, and the daily consumption of these diets were significantly different during the $6 \mathrm{~h}(p=0.00007, n=6)$ and $8 \mathrm{~h}(p=0.00003, n=8)$ consumption period. The total nisin consumption per cage over the course of the trial was 144 \pm 14 and $52 \pm 11 \mathrm{mg}$ for the SD-N and SG-N diet groups, respectively, and the daily consumption of the nisin portion of those diets were also significantly different during the $6 \mathrm{~h}$ $(p=0.0003, n=6)$ and $8 \mathrm{~h}(p=0.00002, n=8)$ consumption period. The average nisin consumption per day per cage during the $8 \mathrm{~h}$ consumption period was $17 \pm 1$ and $6 \pm 2 \mathrm{mg}$ for the SD-N and SG-N diets groups, respectively. Therefore, there was approximately a three-fold greater consumption of nisin by mice on the SD-N diet compared to mice on the SG-N diet. For SD$\mathrm{N}$ compared to SD, SG-N compared to SG and SD compared to SG there were no statistically significant differences during the $6 \mathrm{~h}(p=0.134,0.101$, and 0.217 , respectively, $n=6)$ and $8 \mathrm{~h}$ ( $p=0.507,0.442$, and $0.54, n=8$ ) consumption periods (days 9-15 of the trial).

\section{Identification and Quantification of Intact Nisin and Nisin Fragments in the Feces}

The activity assays of the fecal pellets from mice consuming SD, SD-N, SG, and SG-N diets (Figure 2A) showed antibacterial activity in feces from mice that consumed the SD-N and SG$\mathrm{N}$ diets. MALDI TOF MS was performed on fecal pellets to determine their intact nisin and nisin fragment composition 

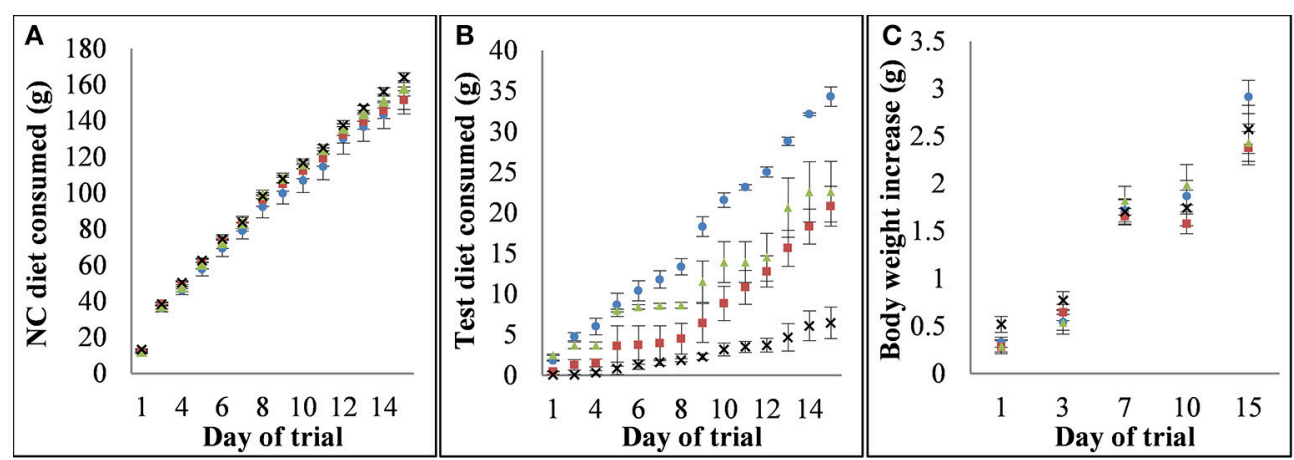

FIGURE 1 | Consumption of each diet and the relationship between diets and weight gain. (A) Cumulative consumption of nutritionally complete (NC) partner diets for each diet group, (B) cumulative consumption of test diets for each diet group, (C) cumulative weight gain for each diet group. Diet groups are defined by their test diet as follows: blue circle - starch dough (SD), red square - starch dough containing nisin (SD-N), green triangle - starch gel (SG), black cross - starch gel containing nisin (SG-N).

(Figures 2B,C). Their primary nisin components were then determined by RP-HPLC in conjunction with MALDI TOF MS (Figures 2D,E). For comparison purposes intact nisin was also analyzed by RP-HPLC in conjunction with MALDI TOF MS (Figures 2F,G).

MALDI TOF MS of the fecal pellets of mice on the SD$\mathrm{N}$ (Figure 2B) and SG-N diets (Figure 2C) showed masses that correlated with intact nisin and nisin fragments 22-31 (i.e., corresponding to amino acids $22-31$ of intact nisin) and 21-31; these nisin fragments are the products of the digestion of nisin and have predicted molecular masses of 1063.47 and $1195.44 \mathrm{Da}$, respectively (Slootweg et al., 2013). Versions of nisin fragment 22-31 with a $\mathrm{Na}$ adduct ion $(+22 \mathrm{Da})$ and a $\mathrm{K}$ adduct ion $(+38 \mathrm{Da})$ were also detected. Intact nisin, extracted from the fecal pellets, was seen in its doubly charged form at 1676.46 and 1675.61 Da for the SD-N diet and for the SG-N, respectively.

RP-HPLC of the fecal pellets of mice on the SG-N diet showed a single dominant peak (Figure 2D) that eluted at $41 \%$ acetonitrile and MALDI TOF MS of this peak revealed it to be nisin fragment 22-31 (Figure 2E). A similar result was obtained for the fecal pellets of mice on the SD-N diet (result not shown). Therefore, the primary nisin component of the feces was fragment 22-31, as opposed to intact nisin.

Intact nisin normally elutes from a RP-HPLC at $36 \%$ acetonitrile (Figure 2F) and subsequent MALDI TOF MS of this elution peak shows both singly (3354.46 Da) and doubly $(1677.68 \mathrm{Da})$ charged intact nisin (Figure 2G). However, while no intact nisin was detected by HPLC, antibacterial activity was detected in the feces of those groups fed the SD-N and SG-N diets (Figure 2A). This would suggest that the nisin concentration in the fecal pellets was below the level of detection by HPLC.

Quantifying the intact nisin in the feces at the final time point based on antibacterial activity showed significantly more $(p=0.031, n=3)$ nisin in the feces of the group fed SG-N $(1.7 \pm$ $0.2 \mathrm{ng} / \mathrm{mg})$ compared to the groups fed SD-N $(0.8 \pm 0.1 \mathrm{ng} / \mathrm{mg})$, despite the fact that less nisin was consumed by the group fed the SG-N diet, which would indicate that more intact nisin reached the lower GIT in SG-N-fed mice. Therefore, at the final time point
( $8 \mathrm{~h}$ test diet period), despite the significantly $(p=0.00002, n=8)$ greater nisin consumption of the mice on the SD-N diets, there was significantly ( $p=0.031, n=3$ ) greater nisin in the feces from consumption of the SG-N diets.

\section{HTS-Based Analysis of Microbiota}

Following total metagenomic DNA extraction from the fecal pellets from day 15, 16S rRNA gene amplicons (V3-V4 region) were generated and sequenced using the Illumina $\mathrm{MiSeq}^{\mathrm{TM}}$ platform. The mean number of sequence reads and alpha diversity indices for each diet group are shown in Table 3. There were no statistical differences in the alpha diversity indices: Observed operational taxonomic units (unique operational taxonomic units), Chaol (richness), ACE (richness), Simpson (richness and evenness), and Shannon (richness and evenness), between the diet groups (Table 3). However, when the beta diversity was calculated using distance matrices built from unweighted UniFrac distances and the PCoA results visualized using EMPeror (Vázquez-Baeza et al., 2013), the four treatment groups formed distinct clusters based on diet (Figure 3), which were significantly different $(p=0.001, n=10)$.

Sequence analysis revealed that the microbiota were primarily comprised of six phyla and that Bacteroidetes and Firmicutes were the dominant phyla showing a relative abundance of 54-62 and $25-33 \%$, respectively. There were no significant differences between the relative abundance of Bacteroidetes and Firmicutes across the diet groups (Figure 4), however there were significant differences $(p<0.001, n=10)$ in the relative abundance between diet groups in the phyla Actinobacteria, Tenericutes, and Verrucomicrobia (Figure 4).

A number of statistical differences were found at genus level between the different dietary groups (Figure 5 and Table 4). The mice fed the SG-N diet had significantly lower relative abundance of the genera Allobaculum, Bifidobacterium, Lachnospiracea incertae sedis, and Clostridium cluster XIVa and significantly higher relative abundance of the genera Escherichia/Shigella, Lactococcus, and Corynebacterium compared to the mice fed the SG diet $(p<0.001, n=10)$. These changes were 

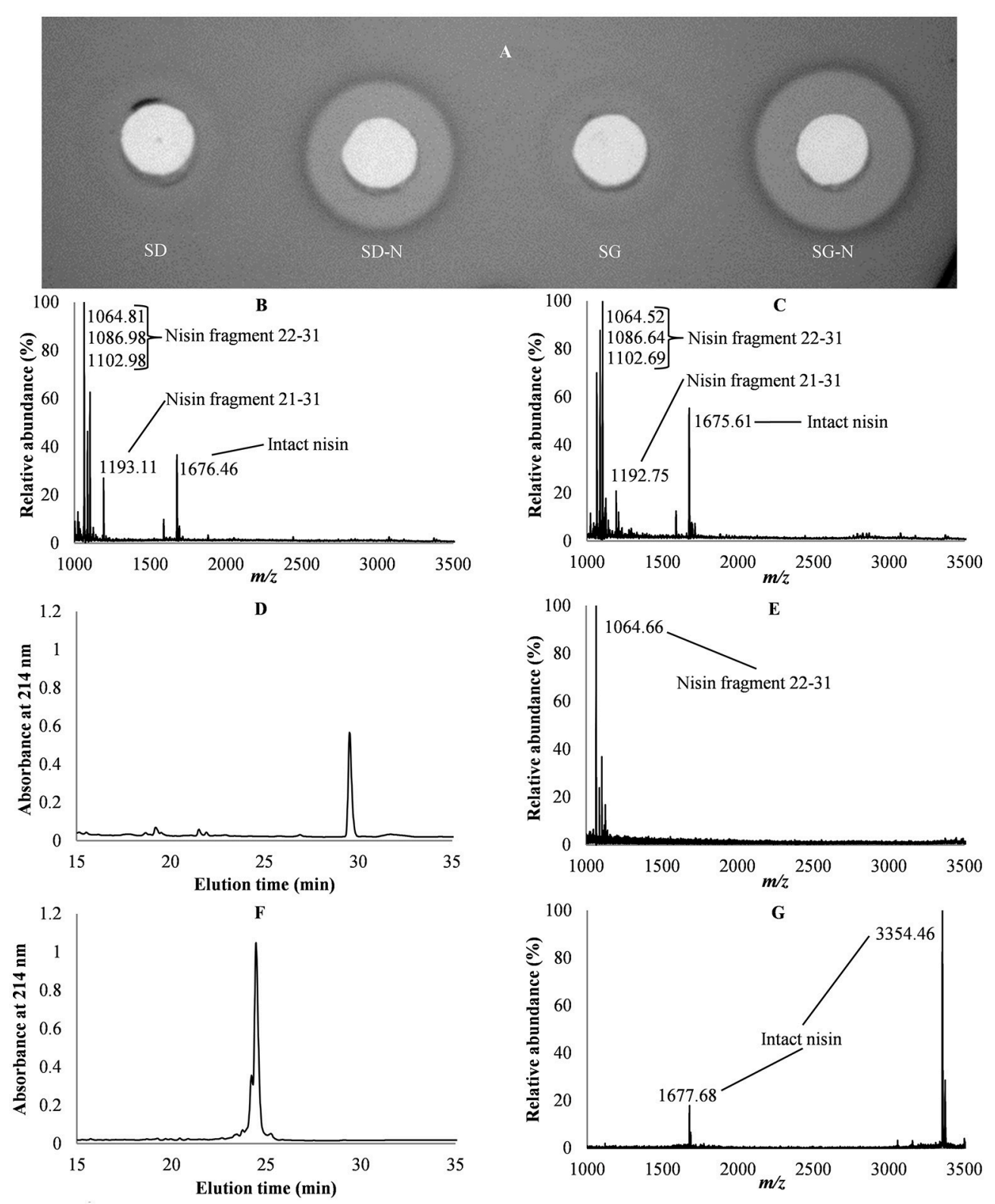

FIGURE 2 | Analysis of fecal pellets of mice consuming starch dough (SD), starch dough containing nisin (SD-N), starch gel (SG), and starch gel containing nisin (SG-N) diets. Activity assay of fecal pellets of mice consuming SD, SD-N, SG, and SG-N diets (A). Mass spectroscopy of fecal pellets from mice consuming SD-N (B) and SG-N diets (C). RP-HPLC chromatogram of fecal pellets from mice consuming SG-N (D) and mass spectroscopy of the elution peak (E). RP-HPLC chromatogram of intact nisin (F) and mass spectroscopy of the elution peak (G).

reflected at the corresponding family level. However, there was also a significantly higher $(p=0.0005, n=10)$ relative abundance of the family Ruminococcaceae (Table 4) in mice fed the SG-N diet that did not correspond to a significant increase of any genus related to the Ruminococcaceae family. This likely reflects the combined increases (not individually statistically significant) in the proportions of the genera Anaerotruncus and Hydrogenoanaerobacterium, i.e., members of the Ruminococcaceae family, in mice that consumed the SG$\mathrm{N}$ diet. Relative to the SD diet, the SD-N diet significantly $(p<0.001, n=10)$ affected the relative abundance of only three genera; i.e., Lactobacillus and Bifidobacterium, which were lower, and Escherichia/Shigella, which were higher (Table 4).

There were also differences between the diet groups when compared on the basis of starch matrix. The relative abundance of the genera Anaeroplasma, Bifidobacterium, and Odoribacter were significantly $(p<0.001, n=10)$ greater in the mice fed the SD diet compared to the SG diet, whereas the relative abundance of the genera Akkermansia, Lachnospiracea incertae sedis, and Parabacteroides were all significantly $(p<0.001, n=10)$ greater 
TABLE 3 | Mean sequence reads and alpha diversity indices for starch dough (SD), starch dough containing nisin (SD-N), starch gel (SG), and starch gel containing nisin (SG-N) diet groups (mean \pm standard error, $n=10$ ).

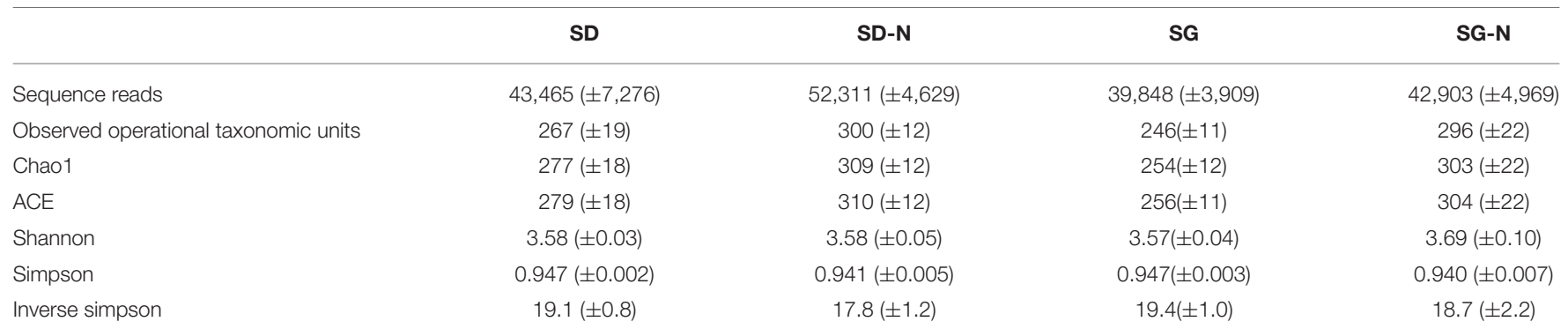

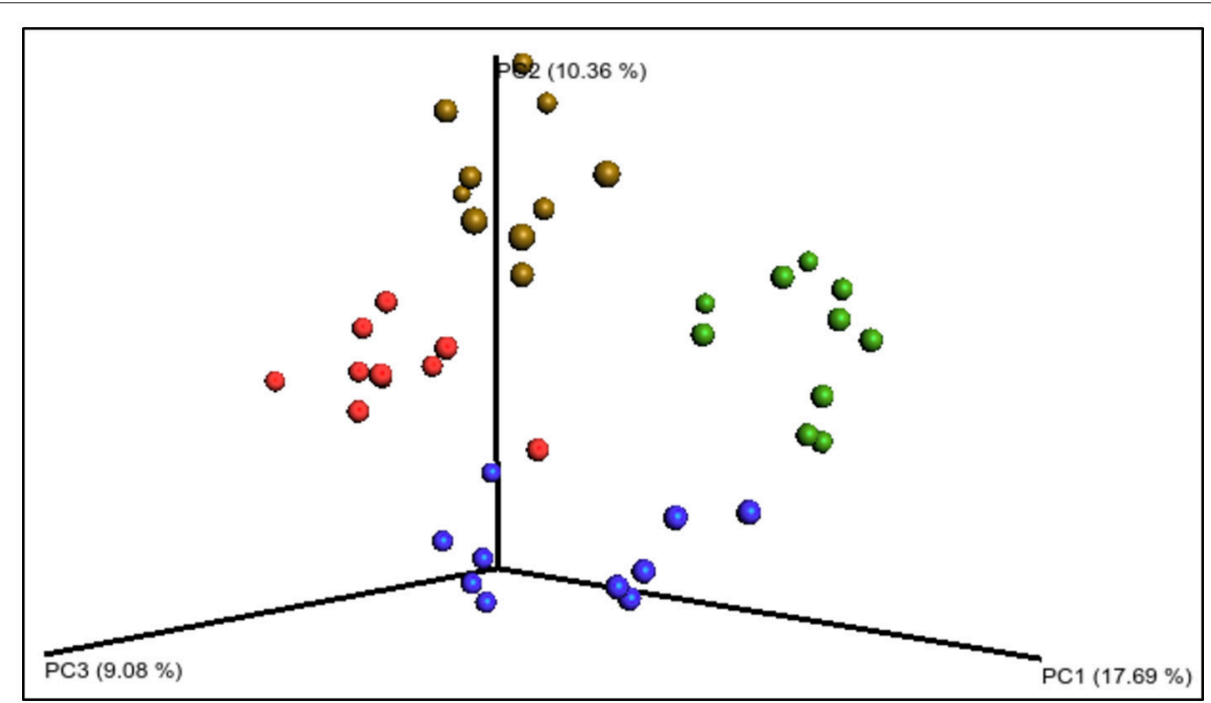

FIGURE 3 | Principal coordinates analysis PCoA of the unweighted UniFrac distances of the 168 sequencing data. The four diet groups are represented by colored circles: blue-starch dough (SD), green-starch dough containing nisin (SD-N), red-starch gel (SG), brown-starch gel containing nisin (SG-N). The groups are significantly different $(p=0.001, n=10)$.

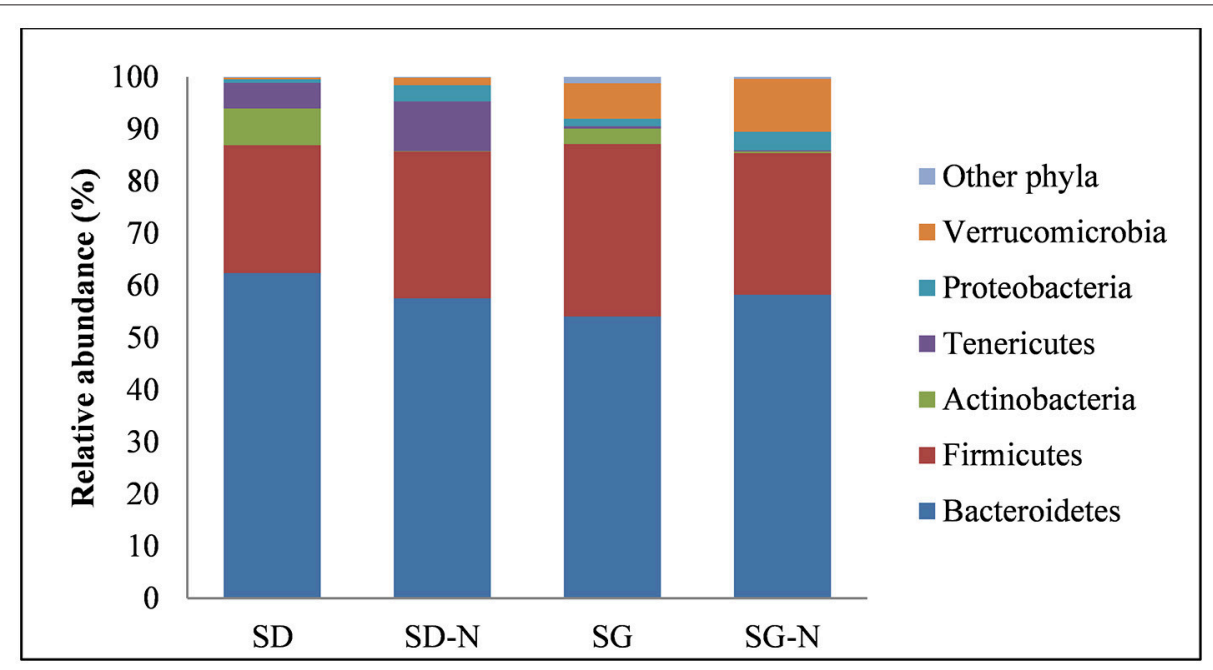

FIGURE 4 | Relative abundance at phylum level with respect to each diet. Diet groups are as follows: starch dough (SD), starch dough containing nisin (SD-N), starch gel (SG), and starch gel containing nisin (SG-N) diet $(n=10)$. 


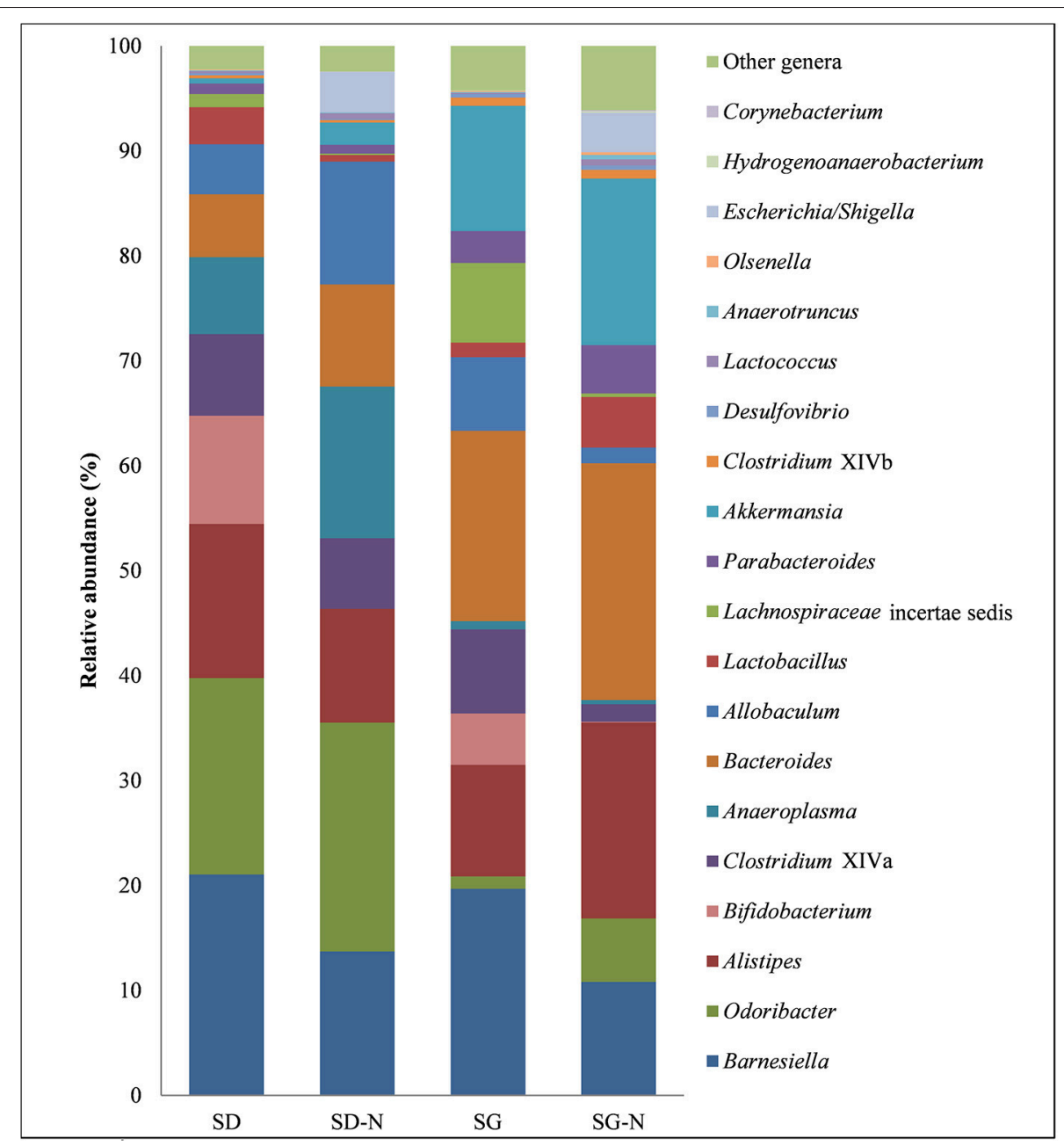

FIGURE 5 | Relative abundance at genus level with respect to each diet. Diet group are as follows: starch dough (SD), starch dough containing nisin (SD-N), starch gel (SG), and starch gel containing nisin (SG-N) diet $(n=10)$.

in the mice fed the SG diet relative to the SD diet (Figure 5 and Table 4). In addition, Clostridium cluster XIVb and Desulfovibrio had greater relative abundance in the mice fed the SG and SG-N diets compared to the mice fed the SD and SD-N diets (Table 4) and this was significantly different $(p<0.001, n=10)$ for the SG-N diet group compared to the SD-N diet group.

\section{DISCUSSION}

The aim of this study was to determine if orally ingested nisin could be delivered to the lower GIT in two different starch matrices and subsequently impact on the lower GIT microbiota. Additionally, it was examined whether the type of starch itself could modulate the lower GIT microbiota.

To the authors' knowledge (Table 1) the only study that has examined the effect of orally ingested nisin on the rodent microbiota is the study on rats by Bernbom et al. (2006), in which the highest amount of nisin consumed was $174 \mathrm{mg}$ nisin per $\mathrm{kg}$ body weight per day and, while nisin was detected in the feces, no changes in the microbiota were detected which may be due to the sensitivity of the molecular methods used in that study. In this study it was hoped that using a 16s HTS approach and similar levels of nisin as described by Bernbom et al. (2006), it would be possible to determine the impact of nisin on the microbiota. All test diets were increased at intervals over the trial to acclimatize the mice to consuming starch and nisin. At the $8 \mathrm{~h}$ consumption period the mice consumed 161 and $54 \mathrm{mg}$ nisin per kg body weight per day for the SD-N and SG-N diets, respectively. To limit the stress on the mice they were allowed unrestricted access to a diet within a given consumption period, however this approach limited a more precise matching of the amount fed to the Bernbom et al. (2006) study.

Numerous studies have shown that nisin is susceptible to digestion by the enzymes in the upper GIT and a previous study by our group using the in vitro INFOGEST digestion model for the human GIT, detected nisin fragments corresponding to the $\mathrm{N}$-terminus of nisin (amino acids 1-11, 1-12, 1-20, 1-21, 1-29, 
TABLE 4 | Bacterial taxa whose relative abundance was significantly different between diet groups.

\begin{tabular}{|c|c|c|c|c|}
\hline & SD & SD-N & SG & SG-N \\
\hline \multicolumn{5}{|l|}{ SIGNIFICANT AT GENUS LEVEL } \\
\hline Akkermansia & $0.499( \pm 0.111) a$ & $2.120( \pm 1.077)$ & $11.943( \pm 2.369) a$ & $15.879( \pm 4.789)$ \\
\hline Allobaculum & $4.764( \pm 0.827)$ & $11.690( \pm 2.107) \mathrm{b}$ & $7.018( \pm 1.245) d$ & $1.504( \pm 0.528) \mathrm{bd}$ \\
\hline Anaeroplasma & 7.307 ( \pm 1.905$) a$ & $14.442( \pm 2.667) \mathrm{b}$ & $0.799( \pm 0.180) \mathrm{a}$ & $0.385( \pm 0.174) b$ \\
\hline Bifidobacterium & $10.317( \pm 0.902) \mathrm{ac}$ & $0.005( \pm 0.001) \mathrm{bc}$ & $4.894( \pm 0.602) \mathrm{ad}$ & $0.090( \pm 0.030) \mathrm{bd}$ \\
\hline Clostridium cluster XIVa & $7.777( \pm 1.044)$ & $6.731( \pm 0.577) \mathrm{b}$ & $8.003( \pm 1.261) d$ & $1.685( \pm 0.646) \mathrm{bd}$ \\
\hline Clostridium cluster XIVb & $0.289( \pm 0.095)$ & $0.226( \pm 0.045) b$ & $0.777( \pm 0.117)$ & $0.831( \pm 0.145) b$ \\
\hline Corynebacterium & $0.007( \pm 0.002)$ & $0.021( \pm 0.007)$ & $0.007( \pm 0.003) d$ & $0.091( \pm 0.018) d$ \\
\hline Desulfovibrio & $0.222( \pm 0.058)$ & $0.119( \pm 0.031) b$ & $0.350( \pm 0.076)$ & $0.415( \pm 0.058) b$ \\
\hline Escherichia/Shigella & $0.009( \pm 0.005) c$ & $3.860( \pm 1.971) c$ & $0.011( \pm 0.002) d$ & $3.771( \pm 1.795) d$ \\
\hline Lachnospiraceae incertae sedis & $1.248( \pm 0.375) \mathrm{a}$ & $0.126( \pm 0.091)$ & $7.579( \pm 1.410) \mathrm{ad}$ & $0.336( \pm 0.281) d$ \\
\hline Lactobacillus & $3.536( \pm 0.470) c$ & $0.643( \pm 0.330) c$ & $1.378( \pm 0.351)$ & $4.828( \pm 3.140)$ \\
\hline Lactococcus & $0.168( \pm 0.024)$ & $0.533( \pm 0.080)$ & $0.095( \pm 0.014) d$ & $0.580( \pm 0.143) d$ \\
\hline Odoribacter & $18.711( \pm 2.515) \mathrm{a}$ & $21.817( \pm 1.322) b$ & $1.164( \pm 0.186) a$ & $6.058( \pm 2.205) b$ \\
\hline Parabacteroides & $0.996( \pm 0.160) a$ & $0.835( \pm 0.108)$ & $3.042( \pm 0.662) a$ & $4.597( \pm 1.200)$ \\
\hline \multicolumn{5}{|c|}{ NOT SIGNIFICANT AT GENUS LEVEL BUT SIGNIFICANT AT FAMILY LEVEL } \\
\hline Ruminococcaceae & $2.285( \pm 0.468)$ & $3.296( \pm 0.420)$ & $2.157( \pm 0.273) d$ & $7.759( \pm 0.684) d$ \\
\hline Unclassified Ruminococcaceae & $1.519( \pm 0.356)$ & $2.228( \pm 0.259)$ & $1.492( \pm 0.201) d$ & $5.284( \pm 0.423) d$ \\
\hline
\end{tabular}

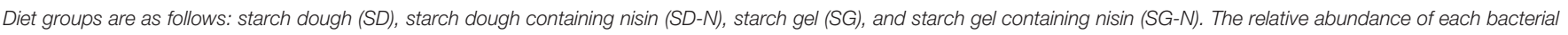

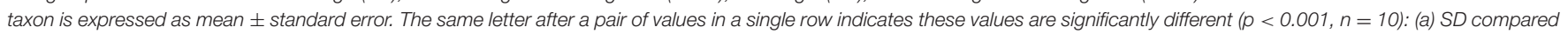
to SG, (b) SD-N compared to SG-N, (c) SD compared to SD-N, and (d) SG compared to SG-N.

and 1-32) post digestion, while no intact nisin was detected (Gough et al., 2017b). In this study, low levels of biologically active nisin (ng/mg of feces) were detected in the feces of mice fed SG-N and SD-N, but, in contrast to the in vitro study, the primary nisin component of the feces was fragment 22-31, which is not biologically active as the $\mathrm{N}$-terminus is required for nisin activity (Hsu et al., 2004). It is also notable that the fragments produced by the in vivo digestion had a significant portion of their C-terminal present whereas those produced by the in vitro digestion had a significant portion of their N-terminal present. These differences can most likely be attributed to species-related differences in digestive enzymes.

More nisin was detected in the fecal samples of the mice on the SG-N diet despite them having consumed less nisin than those on the SD-N diet; implying that more intact nisin reached the lower GIT on the SG-N diet and that the starch gel may have afforded some protection to the nisin from digestion in the upper GIT. To the authors' knowledge there are no reported studies of the in vivo effect of nisin on the gut microbiota using HTS techniques. The results of $16 \mathrm{~S}$ rRNA compositional sequencing showed that alpha diversity indices for all diet groups were comparable to those seen in previous studies on fecal samples from C57BL/6J mice on low-fat diets (Allen et al., 2015; Javurek et al., 2017). Notably, however, beta diversity analysis showed that the murine microbiotas clustered together on the basis of diet. With respect to taxonomy, significant differences in the relative abundance between diet groups were observed for the phyla Actinobacteria, Tenericutes, and Verrucomicrobia $(p<0.001, n=10)$. In each case a single genus, i.e., Bifidobacterium, Anaeroplasma, and Akkermansia, respectively, comprised the majority (>98\%) of the genera detected belonging to these phyla.
There were differences between the cumulative consumption of SD compared to SG (Figure 1B), however as detailed above, those differences were not statistically significant for the 6 and $8 \mathrm{~h}$ consumption periods (days 9-15 of the trial). Resistant starch is known to effect satiety (Lockyer and Nugent, 2017). The hormones glucagon-like peptide 1 (GLP-1) and peptide tyrosinetyrosine (PYY) which are involved in the regulation of satiety and glycemic response (D'Alessio, 2008) have been demonstrated to be elevated by resistant starch consumption in studies on mice (Zhou et al., 2008). Although to the authors knowledge while the relative ability of difference resistant starch types to effect satiety has not been elucidated, it has been shown that different types of resistant starch elicit significantly different glycemic responses (Haub et al., 2010). Therefore, it may be possible that the differences in consumption of the SD and SG are due to differences in the effect of RS2 and RS3 on satiety, however this was not investigated further in this study given our focus on the effects of nisin on the gut microbiota.

There were also differences between the cumulative consumption of SG-N compared to SG, and SD-N compared to SD (Figure 1B), however as detailed above, those differences were not statistically significant for the 6 and $8 \mathrm{~h}$ consumption periods (days $9-15$ of the trial). This reduction in consumption is unlikely to be due to an effect of nisin on the microbiota as such a change in the microbiota would also affect the consumption of the NC diets and there were no statistically significant differences between the consumption of their respective partner NC diets throughout the trial (Figure 1A). While high protein diets have been shown to increase satiety, the level of protein in the nisin containing diets $(\sim 0.58 \%)$ is unlikely to have had an effect on satiety in this case (Batterham et al., 2006; Yu et al., 2009; 
Wiessing et al., 2015). However, it is possible that the palatability of nisin may have contributed to the reduced consumption of the nisin containing diets.

A limitation of this study is that the mice consumed different quantities of each of the test diets (Figure 1B). While this could have confounded the effect of nisin on the microbiota of the diet groups when SD is compared to SD-N and SG is compared to SG-N (Table 4), the changes in the microbiota, nonetheless, are consistent with the specific effect of nisin on these microorganisms. The difference in the amount of starch consumed and resistant starch type could have confounded the effects of the nisin. However, when comparing diets containing dough and gel (Table 4), of the eight genera that showed a significant difference $(p<0.001, n=10)$ in relative abundance, only two genera were also significantly different $(p<0.001$, $n=10)$ in relative abundance when SD-N was compared to SD and SG-N was compared to SG. Additionally, of these two genera, Lachnospiraceae incertae sedis was only significantly different $(p<0.001, n=10)$ in relative abundance in SG-N compared to SG, while Bifidobacterium showed significantly lower $(p<0.001$, $n=10$ ) relative abundance in both the SD-N compared to SD and SG-N compared to SG. It has been reported previously that Bifidobacterium are particularly sensitive to nisin relative to other intestinal bacteria (Le Blay et al., 2007). Furthermore, nisin primarily targets Gram positive bacteria. Interestingly the genera that were significantly lower $(p<0.001, n=10)$ in relative abundance in SD-N compared to SD and SG-N compared to SG (Table 4) were Gram positive or primarily Gram positive (Clostridium cluster XIVa), whereas the genera and family that significantly increased $(p<0.001, n=10)$ in relative abundance in SD-N compared to SD and SG-N compared to SG (Table 4) were either Gram negative (Escherichia/Shigella), contained Gram negative members (Ruminococcaceae) or may have had nisin resistant mechanisms that are known to be present in some strains (Lactococcus and Corynebacterium) (Brenner et al., 2005; De Vos et al., 2009; Goodfellow et al., 2012; Zhou et al., 2014; Draper et al., 2015; Gharsallaoui et al., 2016). Taking these points together, we hypothesize that one reason for the differences in relative abundance between SD-N compared to SD and SG-N compared to SG is the presence or absence of nisin in the test diets.

Starch based doughs have been proposed for use for the oral delivery of drugs to laboratory rodents as a stress free alternative to oral gavage (Corbett et al., 2012). We observed in preliminary in vitro studies, that SD-N when placed in water rapidly dissociated releasing the nisin, whereas SG-N did not dissociate and nisin release was limited. Therefore, it is possible that the nisin would be released earlier and more rapidly from the SD-N than from the SG-N, which would in turn result in more of the nisin being digested in the upper GIT by the digestive enzymes secreted there and therefore impacting less on the microbiota in the lower GIT than nisin incorporated into the SG$\mathrm{N}$. While it is acknowledged that there are difficulties discerning the effect of the rate of release of the starch matrices from the effect of the level of consumption and resistant starch type, the compositional sequencing provides some evidence that nisin was released from the SD-N early in GIT transit and from the SG-N late in GIT transit. The relative abundance of Lactobacillus, which are primarily residents in the upper GIT that in turn transiently populate the lower GIT (Denev, 2006; Walter, 2008), was reduced in the SD-N fed group but were unaffected in the SG-N fed group, which may point to an earlier release in the upper GIT resulting in fewer lactobacilli reaching the colon. Additionally the SG-N diet affected the relative proportion of more than three times as many genera that are primarily resident in the lower GIT than were affected by the SD-N diet (when comparing both with their respective "starch only" controls); this indicates that the SG-N delivered more nisin to the lower GIT than the SD-N. Furthermore, despite there being approximately three-fold lower consumption of nisin by the mice on the SG-N diet compared to the mice on the SD-N diet, there was approximately twice as much nisin detected in the feces of the mice that consumed the SG-N diet compared to those that consumed the SD-N diet.

Bifidobacterium and Escherichia/Shigella were the only two genera significantly ( $p<0.001, n=10)$ different in both the SD-N and SG-N diet groups compared to the SD and SG diet groups. Bifidobacteria have been demonstrated to attenuate Escherichia/Shigella in several studies, including in mice (Gibson and Wang, 1994; Shu and Gill, 2001; Cheikhyoussef et al., 2007). It is possible that a nisin mediated reduction in the relative abundance of bifidobacteria allowed Escherichia/Shigella to increase in relative abundance; particularly as these were the only two genera resident in the lower GIT that were significantly different when the SD-N and SD diet groups were compared.

While it would be interesting to determine whether the changes in the microbiota seen in this study could occur at substantially lower levels of nisin consumption such as those found in food, a dose response study would be required to evaluate this. The current acceptable daily intake (ADI) is $1 \mathrm{mg}$ nisin per kg body weight per day (Younes et al., 2017) while typical levels added to foods range from 2.5 to $25 \mathrm{mg} / \mathrm{kg}$ (DelvesBroughton, 2005).

Resistant starch is capable of modulating the microbiota in the lower GIT and its effect depends on the type of resistant starch (Bird et al., 2000; Martínez et al., 2010). Many of the genera whose relative abundance was significantly different $(p<0.001$, $n=10$ ) when compared on the basis of resistant starch type including Akkermansia, Anaeroplasma, Bifidobacterium, Lachnospiracea, Odoribacter, and Parabacteroides have positive health associations (Leahy et al., 2005; Noor et al., 2010; Kverka et al., 2011; Reeves et al., 2012; Vital et al., 2014; Zeng et al., 2015; Gómez-Gallego et al., 2016). Of particular interest was the alteration in the relative abundance of Akkermansia which has been described as a "next generation probiotic" (Cani and Van Hul, 2015) and is associated with numerous health benefits including treating type 2 diabetes, reducing the occurrence of autoimmune diseases and in weight management (Gómez-Gallego et al., 2016). Akkermansia in the murine gut is generally low (Schubert et al., 2015). Diets that include resistant starch have been shown previously to increase the relative abundance of Akkermansia (Tachon et al., 2013). There was less SG (RS3) consumed than SD (RS2) over the course of the study (Figure 1B), although as detailed above, this difference in consumption was not significant during the 6 or $8 \mathrm{~h}$ consumption 
periods (days 9-15 of the trial), however the relative abundance of Akkermansia was significantly ( $p=0.0002, n=10)$ greater in mice fed the SG (RS3) than the SD (RS2) diet (12 and $0.5 \%$ relative abundance, respectively). This may be attributable to the type of starch, however confirmation of this would require further investigation using $\mathrm{NC}$ diets incorporating the various starch types.

Overall, while it may be possible to attribute the differences in the microbiota between the diet groups to the effects of the diet components, it is important to highlight that these may not all be direct effects. The GIT microbiota is an interdependent community and the effect of a diet component on members of that network may promote other members that were not directly affected by the diet component (Willing et al., 2011; Scott et al., 2015).

Increased body weight gain due to nisin consumption has been demonstrated in previous studies involving chickens and rabbits (Table 1). However, in this study, no effect of nisin on body weight was observed, regardless of the matrix used for delivery. This is consistent with studies involving rats and quails and the majority of studies involving mice (Table $\mathbf{1}$ ).

\section{CONCLUSIONS}

This study showed that by using a starch matrix, nisin can be delivered to the lower GIT and will impact on the lower GIT microbiota. All four diets altered the mouse microbiota differently, with the differences between the two nisin containing diets may be attributable to differences in how nisin was released and protected by the two starch matrices, while the differences between the starch matrices may be attributable to the type of resistant starch (type 2 and type 3 ) favoring the abundance of different bacterial taxa. It was particularly notable how the relative abundance of the probiotic Akkermansia differed between the two resistant starch diets however the difference in consumption between starch diets makes comparisons more difficult and this would need to be addressed in a further study.

\section{REFERENCES}

Abee, T., and Delves-Broughton, J. (2003). "Bacteriocins - nisin," in Food Preservatives, 2nd Edn, eds N. J. Russell and G. W. Gould (New York, NY: Kluwer Academic; Plenum Publishers), 146-178.

Alcázar-Alay, S. C., and Meireles, M. A. A. (2015). Physicochemical properties, modifications and applications of starches from different botanical sources. Food Sci. Technol. 35, 215-236. doi: 10.1590/1678-457X.6749

Allen, J. M., Berg Miller, M. E., Pence, B. D., Whitlock, K., Nehra, V., Gaskins, H. R., et al. (2015). Voluntary and forced exercise differentially alters the gut microbiome in C57BL/6J mice. J. Appl. Physiol. 118, 1059-1066. doi: 10.1152/japplphysiol.01077.2014

Aronesty, E. (2011). ea-utils: Command-line Tools for Processing Biological Sequencing Data. Available online at: https:/github.com/ExpressionAnalysis/ ea-utils

Batterham, R. L., Heffron, H., Kapoor, S., Chivers, J. E., Chandarana, K., Herzog, H., et al. (2006). Critical role for peptide YY in proteinmediated satiation and body-weight regulation. Cell Metabol. 4, 223-233. doi: 10.1016/j.cmet.2006.08.001
Despite greater consumption of the SD-N diet, the SG-N diet resulted in larger amounts of intact nisin in the feces and appeared to affect a greater number of lower GIT bacterial taxa. This highlights the importance of the matrix when studying the activity of a bioactive peptide either as a food additive or as a therapeutic for gastrointestinal pathogens. This study also demonstrated, in an in vivo model, the usefulness of resistant starch, particularly in a retrograded gel, for the colonic delivery of a bioactive peptide. This system may be of use for other heat stable peptides, including those with a narrower range of antimicrobial activity.

\section{AUTHOR CONTRIBUTIONS}

$\mathrm{RG}, \mathrm{AB}, \mathrm{SM}, \mathrm{CH}, \mathrm{RR}, \mathrm{PC}, \mathrm{KN}$, and MR contributed to the design of the experiments. RG, PO, FC, and KN performed the experiments. RG performed statistical analysis of the data. RC performed the bioinformatic analysis of the data. RG, RC, PO, $\mathrm{CH}, \mathrm{RR}, \mathrm{KN}$, and $\mathrm{MR}$ contributed to the interpretation of the data. RG wrote the manuscript. RC, PO, FC, AB, SM, CH, RR, $\mathrm{PC}, \mathrm{KN}$, and $\mathrm{MR}$ revised the manuscript. All authors approved of the final manuscript being submitted and agree to be accountable for the work detailed in the submitted manuscript.

\section{FUNDING}

This work was funded by the Irish Department of Agriculture, Food and the Marine under the FIRM program (grant reference 10/RD/TMFRC/701). RG was funded under the Teagasc Walsh Fellowship scheme (grant reference 2012221). RC, PO, FC, AB, $\mathrm{SM}, \mathrm{CH}, \mathrm{RR}, \mathrm{PC}, \mathrm{KN}$ and MR were funded by Teagasc, Ireland. $\mathrm{RC}, \mathrm{PO}, \mathrm{FC}, \mathrm{CH}, \mathrm{RR}$, and $\mathrm{MR}$ were supported in part by a research grant from Science Foundation Ireland (grant reference SFI/12/RC2273). KN was also funded by Science Foundation Ireland under the grant reference SFI/16/BBSRC/3389 and the UK Biotechnology and Biological Sciences Research Council under grant reference BB/P009875/1.
Bernbom, N., Licht, T. R., Brogren, C. H., Jelle, B., Johansen, A. H., Badiola, I., et al. (2006). Effects of Lactococcus lactis on composition of intestinal microbiota: role of nisin. Appl. Environ. Microbiol. 72, 239-244. doi: 10.1128/AEM.72.1.239-244.2006

Bird, A. R., Brown, I. L., and Topping, D. L. (2000). Starches, resistant starches, the gut microflora and human health. Curr. Issues Intest. Microbiol. 1, 25-37.

Brenner, D. J., Krieg, N. R., Staley, J. T., and Garrity, G. M. (eds.). (2005). Bergey's Manual of Systematic Bacteriology. New York, NY: Springer.

Cani, P. D., and Van Hul, M. (2015). Novel opportunities for next-generation probiotics targeting metabolic syndrome. Curr. Opin. Biotechnol. 32, 21-27. doi: 10.1016/j.copbio.2014.10.006

Caporaso, J. G., Kuczynski, J., Stombaugh, J., Bittinger, K., Bushman, F. D., Costello, E. K., et al. (2010). QIIME allows analysis of highthroughput community sequencing data. Nat. Methods 7, 335-336. doi: 10.1038/nmeth.f.303

Chan, W. C., Leyland, M., Clark, J., Dodd, H. M., Lian, L. Y., Gasson, M. J., et al. (1996). Structure-activity relationships in the peptide antibiotic nisin: antibacterial activity of fragments of nisin. FEBS Lett. 390, 129-132. doi: 10.1016/0014-5793(96)00638-2 
Cheikhyoussef, A., Pogori, N., and Zhang, H. (2007). Study of the inhibition effects of Bifidobacterium supernatants towards growth of Bacillus cereus and Escherichia coli. Int. J. Dairy Sci. 2, 116-125. doi: 10.3923/ijds.2007.116.125

Chung, W. S., Walker, A. W., Louis, P., Parkhill, J., Vermeiren, J., Bosscher, D., et al. (2016). Modulation of the human gut microbiota by dietary fibres occurs at the species level. BMC Biol. 14:3. doi: 10.1186/s12915-015-0224-3

Clarke, S. F., Murphy, E. F., Nilaweera, K., Ross, P. R., Shanahan, F., O’Toole, P. W., et al. (2012). The gut microbiota and its relationship to diet and obesity: new insights. Gut Microbes 3, 186-202. doi: 10.4161/gmic.20168

Corbett, A., McGowin, A., Sieber, S., Flannery, T., and Sibbitt, B. (2012). A method for reliable voluntary oral administration of a fixed dosage $(\mathrm{mg} / \mathrm{kg})$ of chronic daily medication to rats. Lab. Anim. 46, 318-324. doi: 10.1258/la.2012. 012018

Cotter, P. D., Stanton, C., Ross, R. P., and Hill, C. (2012). The impact of antibiotics on the gut microbiota as revealed by high throughput DNA sequencing. Discov. Med. 13, 193-199.

D'Alessio, D. (2008). Intestinal hormones and regulation of satiety: the case for CCK, GLP-1, PYY, and Apo A-IV. J. Parenter. Enteral Nutr. 32, 567-568. doi: $10.1177 / 0148607108322401$

Davies, E. A., Bevis, H. E., Potter, R., Harris, J., Williams, G. C., and DelvesBroughton, J. (1998). Research note: the effect of $\mathrm{pH}$ on the stability of nisin solution during autoclaving. Lett. Appl. Microbiol. 27, 186-187.

Delcour, J. A., Bruneel, C., Derde, L. J., Gomand, S. V., Pareyt, B., Putseys, J. A., et al. (2010). Fate of starch in food processing: from raw materials to final food products. Annu. Rev. Food Sci. Technol. 1, 87-111. doi: 10.1146/annurev.food.102308.124211

Delves-Broughton, J. (2005). Nisin as a food preservative. Food Aust. 57, 525-527.

Denev, S. A. (2006). Role of Lactobacilli in gastrointestinal ecosystem. Bulgarian J. Agric. Sci. 12, 63-114.

de Pablo, M. A., Gaforio, J. J., Gallego, A. M., Ortega, E., Galvez, A. M., and Alvarez de Cienfuegos López, G. (1999). Evaluation of immunomodulatory effects of nisin-containing diets on mice. FEMS Immunol. Med. Microbiol. 24, 35-42. doi: 10.1111/j.1574-695X.1999.tb01262.x

Desai, K. G. (2005). Preparation and characteristics of high-amylose corn starch/pectin blend microparticles: a technical note. Aaps Pharmscitech. 6, E202-E208. doi: 10.1208/pt060230

De Vos, P., Garrity, G. M., Jones, D., Krieg, N. R., Ludwig, W., Rainey, F. A., et al. (eds.). (2009). Bergey's Manual of Systematic Bacteriology. New York, NY: Springer.

Dimantov, A., Greenberg, M., Kesselman, E., and Shimoni, E. (2004). Study of high amylose corn starch as food grade enteric coating in a microcapsule model system. Innov. Food Sci. Emerg. Technol. 5, 93-100. doi: 10.1016/j.ifset.2003.11.003

Draper, L. A., Cotter, P. D., Hill, C., and Ross, R. P. (2015). Lantibiotic resistance. Microbiol. Mol. Biol. Rev. 79, 171-191. doi: 10.1128/MMBR.00 051-14

Edgar, R. C. (2010). Search and clustering orders of magnitude faster than BLAST. Bioinformatics 26, 2460-2461. doi: 10.1093/bioinformatics/ btq461

Field, D., Begley, M., O’Connor, P. M., Daly, K. M., Hugenholtz, F., Cotter, P. D., et al. (2012). Bioengineered nisin A derivatives with enhanced activity against both gram positive and gram negative pathogens. PLOS ONE 7:e46884. doi: 10.1371/journal.pone.0046884

Forssell, P. (2004). "Starch-based microencapsulation," in Starch in Food, ed A.-C. Eliasson (Abington, UK: Woodhead Publishing), 461-473.

Freire, C., Podczeck, F., Ferreira, D., Veiga, F., Sousa, J., and Pena, A. (2010). Assessment of the in-vivo drug release from pellets film-coated with a dispersion of high amylose starch and ethylcellulose for potential colon delivery. J. Pharm. Pharmacol. 62, 55-61. doi: 10.1211/jpp.62.01.0005

Gharsallaoui, A., Oulahal, N., Joly, C., and Degraeve, P. (2016). Nisin as a food preservative: part 1: physicochemical properties, antimicrobial activity, and main uses. Crit. Rev. Food Sci. Nutr. 56, 1262-1274. doi: 10.1080/10408398.2013.763765

Gibson, G. R., and Wang, X. (1994). Regulatory effects of bifidobacteria on the growth of other colonic bacteria. J. Appl. Bacteriol. 77, 412-420. doi: 10.1111/j.1365-2672.1994.tb03443.x

Gómez-Gallego, C., Pohl, S., Salminen, S., De Vos, W. M., and Kneifel, W. (2016). Akkermansia muciniphila: a novel functional microbe with probiotic properties. Benef. Microbes 7, 571-584. doi: 10.3920/BM201 6.0009

Goodfellow, M., Kämpfer, P., Busse, H.-J., Trujillo, M. E., Suzuki, K.-i., Ludwig, W., et al. (eds.). (2012). Bergey's Manual of Systematic Bacteriology. New York, NY: Springer.

Gough, R., Gómez-Sala, B., O'Connor, P. M., Rea, M. C., Miao, S., Hill, C., et al. (2017a). A simple method for the purification of nisin. Probiotics Antimicrob. Proteins 9, 363-369. doi: 10.1007/s12602-017-9287-5

Gough, R., O'Connor, P. M., Rea, M. C., Gómez-Sala, B., Miao, S., Hill, C., et al. (2017b). Simulated gastrointestinal digestion of nisin and interaction between nisin and bile. LWT Food Sci. Technol. 86, 530-537. doi: 10.1016/j.lwt.2017.08.031

Gupta, S. M., Aranha, C. C., and Reddy, K. V. (2008). Evaluation of developmental toxicity of microbicide nisin in rats. Food Chem. Toxicol. 46, 598-603. doi: 10.1016/j.fct.2007.09.006

Hagiwara, A., Imai, N., Nakashima, H., Toda, Y., Kawabe, M., Furukawa, F., et al. (2010). A 90-day oral toxicity study of nisin A, an antimicrobial peptide derived from Lactococcus lactis subsp lactis, in F344 rats. Food Chem. Toxicol. 48, 2421-2428. doi: 10.1016/j.fct.2010. 06.002

Haub, M. D., Hubach, K. L., Al-Tamimi, E. K., Ornelas, S., and Seib, P. A. (2010). Different types of resistant starch elicit different glucose reponses in humans. J. Nutr. Metab. 2010:230501. doi: 10.1155/2010/230501

Heinemann, B., and Williams, R. (1966). Inactivation of nisin by pancreatin. J. Dairy Sci. 49, 312-314. doi: 10.3168/jds.S0022-0302(66)87854-2

Hsu, S. T., Breukink, E., Tischenko, E., Lutters, M. A. G., de Kruijff, B., Kaptein, R., et al. (2004). The nisin-lipid II complex reveals a pyrophosphate cage that provides a blueprint for novel antibiotics. Nat. Struct. Mol. Biol. 11, 963-967. doi: $10.1038 / \mathrm{nsmb} 830$

Jandhyala, S. M., Talukdar, R., Subramanyam, C., Vuyyuru, H., Sasikala, M., and Nageshwar Reddy, D. (2015). Role of the normal gut microbiota. World J. Gastroenterol. 21, 8787-8803. doi: 10.3748/wjg.v21.i29.8787

Jarvis, B., and Mahoney, R. R. (1969). Inactivation of nisin by alphachymotrypsin. J. Dairy Sci. 52, 1448-1450. doi: 10.3168/jds.S0022-0302(69)8 6771-8

Javurek, A. B., Spollen, W. G., Johnson, S. A., Bivens, N. J., Bromert, K. H., Givan, S. A., et al. (2017). Consumption of a high-fat diet alters the seminal fluid and gut microbiomes in male mice. Reprod. Fertil. Dev. 29, 1602-1612. doi: $10.1071 / R D 16119$

Józefiak, D., Kieronczyk, B., Juśkiewicz, J., Zdunczyk, Z., Rawski, M., Długosz, J., et al. (2013). Dietary nisin modulates the gastrointestinal microbial ecology and enhances growth performance of the broiler chickens. PLOS ONE 8:e85347. doi: 10.1371/journal.pone.0085347

Kieronczyk, B., Pruszynska-Oszmalek, E., Swiatkiewicz, S., Rawski, M., Dlugosz, J., Engberg, R. M., et al. (2016). The nisin improves broiler chicken growth performance and interacts with salinomycin in terms of gastrointestinal tract microbiota composition. J. Anim. Feed Sci. 25, 309-316. doi: $10.22358 /$ jafs/67802/2016

Kverka, M., Zakostelska, Z., Klimesova, K., Sokol, D., Hudcovic, T., Hrncir, T., et al. (2011). Oral administration of Parabacteroides distasonis antigens attenuates experimental murine colitis through modulation of immunity and microbiota composition. Clin. Exp. Immunol. 163, 250-259. doi: 10.1111/j.1365-2249.2010.04286.x

Lauková, A., Chrastinová, L., Plachá, I., Kandricáková, A., Szabóová, R., Strompfová, V., et al. (2014). Beneficial effect of lantibiotic nisin in rabbit husbandry. Probiotics Antimicrob. Proteins 6, 41-46. doi: 10.1007/s12602-014-9156-4

Leahy, S. C., Higgins, D. G., Fitzgerald, G. F., and van Sinderen, D. (2005). Getting better with Bifidobacteria. J. Appl. Microbiol. 98, 1303-1315. doi: 10.1111/j.1365-2672.2005.02600.x

Le Blay, G., Lacroix, C., Zihler, A., and Fliss, I. (2007). In vitro inhibition activity of nisin A, nisin Z, pediocin PA-1 and antibiotics against common intestinal bacteria. Lett. Appl. Microbiol. 45, 252-257. doi: 10.1111/j.1472-765X.2007.02178.x

Le Lay, C., Fernandez, B., Hammami, R., Ouellette, M., and Fliss, I. (2015). On Lactococcus lactis UL719 competitivity and nisin (Nisaplin (R) capacity to inhibit Clostridium difficile in a model of human colon. Front. Microbiol. 6:1020. doi: 10.3389/fmicb.2015.01020 
Lillie, L. E., Temple, N. J., and Florence, L. Z. (1996). Reference values for young normal Sprague-Dawley rats: weight gain, hematology and clinical chemistry. Hum. Exp. Toxicol. 15, 612-616. doi: 10.1177/0960327196015 00802

Lockyer, S., and Nugent, A. P. (2017). Health effects of resistant starch. Nutr. Bull. 42, 10-41. doi: 10.1111/nbu.12244

Martínez, I., Kim, J., Duffy, P. R., Schlegel, V. L., and Walter, J. (2010). Resistant starches types 2 and 4 have differential effects on the composition of the fecal microbiota in human subjects. PLoS ONE 5:e15046. doi: 10.1371/journal.pone.0015046

McCleary, B. V., McNally, M., and Rossiter, P. (2002). Measurement of resistant starch by enzymatic digestion in starch and selected plant materials: collaborative study. J. AOAC Int. 85, 1103-1111.

Milojevic, S., Newton, J. M., Cummings, J. H., Gibson, G. R., Botham, R. L., Ring, S. G., et al. (1996). Amylose as a coating for drug delivery to the colon: preparation and in vitro evaluation using 5 -aminosalicylic acid pellets. J. Control. Release 38, 75-84. doi: 10.1016/0168-3659(95)00112-3

Nicholson, J. K., Holmes, E., Kinross, J., Burcelin, R., Gibson, G., Jia, W., et al. (2012). Host-gut microbiota metabolic interactions. Science 336, 1262-1267. doi: $10.1126 /$ science. 1223813

Noor, S. O., Ridgway, K., Scovell, L., Kemsley, E. K., Lund, E. K., Jamieson, C., et al. (2010). Ulcerative colitis and irritable bowel patients exhibit distinct abnormalities of the gut microbiota. BMC Gastroenterol. 10:134. doi: 10.1186/1471-230X-10-134

Oksanen, J., Blanchet, F. G., Kindt, R., Legendre, P., Minchin, P., O'Hara, R. B., et al. (2015). Vegan: Community Ecology Package, Version 2.2-1. Available online at: https://CRAN.R-project.org/package=vegan

Ozdogan, M., and Ustundag, A. O. (2015). Effects of bacteriocin and organic acids on growth performance of Japanese quails. Sci. Papers Series D Anim. Sci. 58, 164-169.

Pu, H. Y., Chen, L., Li, X., Xie, F., Yu, L., and Li, L. (2011). An oral colon-targeting controlled release system based on resistant starch acetate: synthetization, characterization, and preparation of filmcoating pellets. J. Agric. Food Chem. 59, 5738-5745. doi: 10.1021/jf20 05468

R Core Team (2015). R: A Language and Environment for Statistical Computing. Vienna: R Foundation for Statistical Computing. Available online at: https:// www.r-project.org/

Rea, M. C., Alemayehu, D., Casey, P. G., O’Connor, P. M., Lawlor, P. G., Walsh, M., et al. (2014). Bioavailability of the anti-clostridial bacteriocin thuricin CD in gastrointestinal tract. Microbiology 160, 439-445. doi: 10.1099/mic.0.06 $8767-0$

Recife, A. C. D., Meneguin, A. B., Cury, B. S. F., and Evangelista, R. C. (2017). Evaluation of retrograded starch as excipient for controlled release matrix tablets. J. Drug Deliv. Sci. Technol. 40, 83-94. doi: 10.1016/j.jddst.2017. 06.003

Reddy, K. V., Gupta, S. M., and Aranha, C. C. (2011). Effect of antimicrobial peptide, nisin, on the reproductive functions of rats. ISRN Vet. Sci. 2011:828736. doi: $10.5402 / 2011 / 828736$

Reddy, K. V., Aranha, C., Gupta, S. M., and Yedery, R. D. (2004). Evaluation of antimicrobial peptide nisin as a safe vaginal contraceptive agent in rabbits: in vitro and in vivo studies. Reproduction 128, 117-126. doi: 10.1530/rep.1.00028

Reeves, A. E., Koenigsknecht, M. J., Bergin, I. L., and Young, V. B. (2012). Suppression of Clostridium difficile in the gastrointestinal tracts of germfree mice inoculated with a murine isolate from the family Lachnospiraceae. Infect. Immun. 80, 3786-3794. doi: 10.1128/IAI.00 $647-12$

Ryan, M. P., Rea, M. C., Hill, C., and Ross, R. P. (1996). An application in cheddar cheese manufacture for a strain of Lactococcus lactis producing a novel broad-spectrum bacteriocin, lacticin 3147. Appl. Environ. Microbiol.. 62, 612-619.

Sajilata, M. G., Singhal, R. S., and Kulkarni, P. R. (2006). Resistant starch - a review. Compr. Rev. Food Sci. Food Saf. 5, 1-17. doi: 10.1111/j.1541-4337.2006.tb00076.x

Schmieder, R., and Edwards, R. (2011). Quality control and preprocessing of metagenomic datasets. Bioinformatics 27, 863-864. doi: 10.1093/bioinformatics/btr026
Scott, K. P., Antoine, J. M., Midtvedt, T., and van Hemert, S. (2015). Manipulating the gut microbiota to maintain health and treat disease. Microb. Ecol. Health Dis. 26:25877. doi: 10.3402/mehd.v26.25877

Schubert, A. M., Sinani, H., and Schloss, P. D. (2015). Antibiotic-induced alterations of the murine gut microbiota and subsequent effects on colonization resistance against Clostridium difficile. mBio 6:4. doi: 10.1128/mBio.00974-15

Shen, J., Liu, Z., Yu, Z., and Zhu, W. (2017). Monensin and nisin affect rumen fermentation and microbiota differently in vitro. Front. Microbiol. 8:1111. doi: 10.3389/fmicb.2017.01111

Shtenberg, A. J., and Ignatev, A. D. (1970). Toxicological evaluation of some combinations of food preservatives. Food Cosmet. Toxicol. 8, 369-380. doi: 10.1016/S0015-6264(70)80390-X

Shu, Q., and Gill, H. S. (2001). A dietary probiotic (Bifidobacterium lactis HN019) reduces the severity of Escherichia coli O157:H7 infection in mice. Med. Microbiol. Immunol. 189, 147-152. doi: 10.1007/s430-001-8021-9

Sibley, E. (2004). "Carbohydrate digestion and absorption," in Encyclopedia of Gastroenterology, ed L. R. Johnson (New York, NY: Elsevier), 275-278.

Situ, W., Chen, L., Wang, X., and Li, X. (2014). Resistant starch film-coated microparticles for an oral colon-specific polypeptide delivery system and its release behaviors. J. Agric. Food Chem. 62, 3599-3609. doi: 10.1021/jf50 $0472 b$

Slootweg, J. C., Liskamp, R. M., and Rijkers, D. T. (2013). Scalable purification of the lantibiotic nisin and isolation of chemical/enzymatic cleavage fragments suitable for semi-synthesis. J. Peptide Sci. 19, 692-699. doi: 10.1002/psc.2551

Suzuki, T. A., and Nachman, M. W. (2016). Spatial heterogeneity of gut microbial composition along the gastrointestinal tract in natural populations of house mice. PLoS ONE 11:e0163720. doi: 10.1371/journal.pone.0163720

Tachon, S., Zhou, J. N., Keenan, M., Martin, R., and Marco, M. L. (2013). The intestinal microbiota in aged mice is modulated by dietary resistant starch and correlated with improvements in host responses. FEMS Microbiol. Ecol. 83, 299-309. doi: 10.1111/j.1574-6941.2012.01475.x

US Food and Drug Administration (1988). Nisin preparation; affirmation of GRAS status as a direct human food ingredient. Fed. Regist. 53, 11247-11251.

van Staden, D. A., Brand, A. M., Endo, A., and Dicks, L. M. (2011). Nisin F, intraperitoneally injected, may have a stabilizing effect on the bacterial population in the gastro-intestinal tract, as determined in a preliminary study with mice as model. Lett. Appl. Microbiol. 53, 198-201. doi: 10.1111/j.1472-765X.2011.03091.x

Vázquez-Baeza, Y., Pirrung, M., Gonzalez, A., and Knight, R. (2013). EMPeror: a tool for visualizing high-throughput microbial community data. Gigascience 2:16. doi: $10.1186 / 2047-217 X-2-16$

Vital, M., Howe, A. C., and Tiedje, J. M. (2014). Revealing the bacterial butyrate synthesis pathways by analyzing (meta)genomic data. MBio 5:e00889-14. doi: $10.1128 / \mathrm{mBio} .00889-14$

Walter, J. (2008). Ecological role of Lactobacilli in the gastrointestinal tract: implications for fundamental and biomedical research. Appl. Environ. Microbiol. 74, 4985-4996. doi: 10.1128/AEM.00753-08

Wang, Q., Garrity, G. M., Tiedje, J. M., and Cole, J. R. (2007). Naive Bayesian classifier for rapid assignment of rRNA sequences into the new bacterial taxonomy. Appl. Environ. Microbiol. 73, 5261-5267. doi: 10.1128/AEM.00062-07

Wang, S. J., Li, C. L., Copeland, L., Niu, Q., and Wang, S. (2015). Starch retrogradation: a comprehensive review. Compr. Rev. Food Sci. Food Saf. 14, 568-585. doi: 10.1111/1541-4337.12143

Wiessing, K. R., Xin, L., Budgett, S. C., and Poppitt, S. D. (2015). No evidence of enhanced satiety following whey protein- or sucrose-enriched water beverages: a dose response trial in overweight women. Eur. J. Clin. Nutr. 69, 1238-1243. doi: 10.1038/ejen.2015.107

Willing, B. P., Russell, S. L., and Finlay, B. B. (2011). Shifting the balance: antibiotic effects on host-microbiota mutualism. Nat. Rev. Microbiol. 9, 233-243. doi: $10.1038 /$ nrmicro2536

Wilson, P. J., and Basit, A. W. (2005). Exploiting gastrointestinal bacteria to target drugs to the colon: an in vitro study using amylose coated tablets. Int. J. Pharm. 300, 89-94. doi: 10.1016/j.ijpharm.2005.05.010

Younes, M., Aggett, P., Aguilar, F., Crebelli, R., Dusemund, B., Filipič, M., et al. (2017). Safety of nisin (E 234) as a food additive in the light of new toxicological data and the proposed extension of use. EFSA J. 15:5063. doi: $10.2903 /$ j.efsa.2017.5063 
Yu, Y., South, T., and Huang, X. F. (2009). Inter-meal interval is increased in mice fed a high whey, as opposed to soy and gluten, protein diets. Appetite 52, 372-379. doi: 10.1016/j.appet.2008.11.011

Zeng, B., Han, S., Wang, P., Wen, B., Jian, W., Guo, W., et al. (2015). The bacterial communities associated with fecal types and body weight of rex rabbits. Sci. Rep. 5:9342. doi: 10.1038/srep09342

Zhou, H., Fang, J., Tian, Y., and Lu, X. Y. (2014). Mechanisms of nisin resistance in Gram-positive bacteria. Ann. Microbiol. 64, 413-420. doi: 10.1007/s13213-013-0679-9

Zhou, J., Martin, R. J., Tulley, R. T., Raggio, A. M., McCutcheon, K. L., Shen, L., et al. (2008). Dietary resistant starch upregulates total GLP-1 and PYY in a sustained day-long manner through fermentation in rodents. Am. J. Physiol. Endocrinol. Metabol. 295, E1160-E1166. doi: 10.1152/ajpendo.90637.2008
Conflict of Interest Statement: The authors declare that the research was conducted in the absence of any commercial or financial relationships that could be construed as a potential conflict of interest.

The reviewer GG and handling Editor declared their shared affiliation.

Copyright (C) 2018 Gough, Cabrera Rubio, O’Connor, Crispie, Brodkorb, Miao, Hill, Ross, Cotter, Nilaweera and Rea. This is an open-access article distributed under the terms of the Creative Commons Attribution License (CC BY). The use, distribution or reproduction in other forums is permitted, provided the original author(s) and the copyright owner are credited and that the original publication in this journal is cited, in accordance with accepted academic practice. No use, distribution or reproduction is permitted which does not comply with these terms. 